\title{
The Effects of Market Competition on Cardiologists' Adoption of Transcatheter Aortic Valve Replacement
}

\author{
Peter W. Groeneveld, MD, MS ${ }^{1,2,3,4}$, Lin Yang, MS ${ }^{1,2}$, Andrea Segal, MS, MPH ${ }^{1,2,4}$, Pinar \\ Karaca-Mandic, $\mathbf{P h D}^{5,6}$, Genevieve P. Kanter, $\mathbf{P h D}^{1,2,3,7}$ \\ 1)Division of General Internal Medicine, Perelman School of Medicine, University of Pennsylvania, \\ Philadelphia, PA \\ 2)Cardiovascular Outcomes, Quality, and Evaluation Research Center, University of Pennsylvania \\ School of Medicine, Philadelphia, PA \\ 3)Leonard Davis Institute of Health Economics, Philadelphia, PA \\ ${ }^{4)}$ Corporal Michael J. Crescenz Veterans Affairs Medical Center, Philadelphia, PA \\ 5)University of Minnesota Carlson School of Management, Minneapolis, MN \\ 6)National Bureau of Economic Research \\ 7)Department of Medical Ethics and Health Policy, Perelman School of Medicine, University of \\ Pennsylvania, Philadelphia, PA
}

\begin{abstract}
Background.-For decades, the prevailing assumption regarding the diffusion of high-cost medical technologies has been that competitive markets favor more aggressive adoption of new treatments by health care providers (i.e. the "Medical Arms Race"). However, novel regulations governing adoption of Transcatheter Aortic Valve Replacement (TAVR) may have disrupted this paradigm when TAVR was introduced.
\end{abstract}

Objectives.-To assess the relationship between market concentration of physician group practices and the adoption of TAVR in its first years of use.

Research Design.-Retrospective cohort study.

Subjects.-Physician group practices $(\mathrm{n}=5,116)$ providing interventional cardiology services in the United States from May 1, 2012 to December 31, 2014.

\begin{abstract}
Measures.-First use of TAVR as indicated by a fee-for-service Medicare claim. Covariates including characteristics of the physician groups (i.e., case volume, hospital affiliation, mean patient risk) as well county-level and market-level characteristics.
\end{abstract}

Address for Correspondence / Reprints: Peter W. Groeneveld, MD, MS, 1204 Blockley Hall, 423 Guardian Drive, Philadelphia, PA 19104, Tel: 215-898-2569 Fax: 215-573-8778, petergro@upenn.edu.

Conflicts of Interest: Dr. Karaca-Mandic provided consulting services to Tactile Medical and Precision Health Economics for projects unrelated to this work. The other authors have no conflicts of interest to disclose. 
Results.-By the close of 2014, 9.3\% of practices had adopted TAVR. Cox proportional hazards models revealed a hazard ratio of 1.26 (95\% confidence interval 1.16 to $1.37, \mathrm{p}<0.001$ ) per 1,000 point increase in the physician group practice Herfindahl-Hirschman Index (HHI), indicating each 1,000 point increase in group practice $\mathrm{HHI}$ was associated with a $26 \%$ relative increase in the rate of TAVR adoption.

Conclusions.-Adoption of TAVR by physician groups in concentrated markets was potentially a consequence of the unique regulations governing TAVR reimbursement, which favored the adoption of TAVR by physician groups with greater market power. These findings have important implications for how future regulations may shape patterns of technology adoption.

\section{Keywords}

cardiology; health care markets; integrated health care; market competition; physician practice patterns; technology

Transcatheter aortic valve replacement (TAVR) was introduced into clinical practice in 2011-2012 as an alternative therapy to standard aortic valve replacement for patients with aortic stenosis deemed at high risk for perioperative complications (1). The 2011 Food and Drug Administration's initial approval of TAVR (2), and subsequent 2012 Centers for Medicare and Medicaid Services (CMS) National Coverage Determination (3), presented an opportunity for interventional cardiology physician groups to expand their repertoire of clinical services to include this high-profile and potentially lucrative new procedure. Medicare reimbursed physicians for TAVR at a relatively high relative-value-unit-based fee compared to other interventional cardiology physician services (4), and since TAVR was a potential substitute for cardiac surgery it represented an opportunity for cardiologists to expand practice into a clinical domain previously occupied exclusively by cardiac surgeons. However, CMS also established an extensive set of clinical, structural (e.g., on-site cardiac surgery) experiential (e.g., sufficient prior case volume of similar procedures), and administrative (e.g., registry participation) requirements for physicians and hospitals to qualify for TAVR reimbursement (3), hence there were also substantial barriers to physician groups interested in providing TAVR.

Prior evaluations of medical technology adoption have generally found that in fee-forservice environments, health care markets with higher levels of competition among hospitals had more rapid adoption than less competitive markets (5-10), in what has colloquially been described as the "Medical Arms Race" (11). While this phenomenon generally has been associated with overuse of medical technology (i.e., use of technology that provides no benefit) (12), in the case of TAVR the adoption of the procedure by an excessive number of interventional cardiology groups in competitive markets could have important adverse quality consequences because the total number of eligible patients in any market is limited, and lower case volumes often result in sub-optimal patient outcomes from complex cardiovascular procedures $(13,14)$.

The purpose of our study was to examine TAVR adoption among interventional cardiology practices during its first years of non-experimental use (i.e., 2012-2014) to determine if market competition was a significant adoption driver. 


\section{METHODS}

\section{Cohort Selection}

To identify physician groups that were candidates for TAVR adoption in 2012-2014, we first selected a cohort of physicians who had Medicare Part B (i.e., provider) claims with Current Procedural Terminology (CPT) codes indicating the physician had performed interventional cardiology procedures (coronary angiography, percutaneous coronary intervention, and/or catheter-delivered structural heart disease repair) among fee-for-service Medicare beneficiaries in 2011 (Appendix 1). Because of occasional CPT coding errors on these claims, we required a minimum of five paid fee-for-service Medicare claims for interventional cardiovascular services in 2011 to classify a physician as an interventional cardiologist. We restricted the cohort to physicians in the contiguous 48 states or the District of Columbia as indicated by the location of the plurality of their Medicare Part B claims. We further restricted the cohort to physicians who remained in practice during 2012-2014 as evidenced by their submitting at least five Part B claims to Medicare during these three years. While non-cardiologists (i.e., surgeons) also provide TAVR, Medicare requires the participation of an interventional cardiologist at each TAVR procedure (3), thus we focused this analysis solely on physician groups with interventional cardiologists.

\section{Identification of Physician Group Practices, and Group Practice Characteristics.}

For each physician identified using the methods described above, the most common Federal Tax Identification Number (TIN) reported on his/her Part B claims during 2012-2014 was used to identify the physician's group practice. The Federal TIN indicates the billing entity that will receive payment for the medical service; the range of physicians represented by a particular TIN can range from 1 (for a physician in a solo practice) to potentially over 1000 in large, multi-specialty integrated health systems.

\section{Group Practice Characteristics}

For each group practice identified following the methods described above, we used 2011 Medicare Part B claims to determine if the group had prior experience providing structural heart repair (e.g., repair of patent foramen ovale, etc.), since CMS required experience in providing such procedures for physicians seeking to provide TAVR (3). The group's interventional cardiology case volume was estimated by counting the number of unique Medicare beneficiaries with an interventional cardiology procedural claim from all physicians affiliated with the practice. The mean comorbidity of the group's Medicare patient population was estimated by calculating a mean CMS Hierarchical Condition Category risk score for all patients in 2011 with a billed clinical encounter with interventional cardiologists affiliated with the group (15), including both patients who had undergone interventional procedures as well as those who did not.

\section{Hospital Identification and Characteristics}

Because physician groups may have been strongly influenced by their affiliated hospitals, each group's primary affiliated hospital was identified by using the Medicare Part A claim linked by patient identifier and date to a physician group's Part B claim for an interventional 
cardiology procedure, to determine the hospital where the plurality of each physician group's interventional cardiology procedures were performed among fee-for-service Medicare beneficiaries in 2011. Membership in the Council of Teaching Hospitals and Health Systems in 2012 as indicated by the American Hospital Association's annual survey was used as an indicator of which hospitals were academic centers. Published lists of the participating hospitals in the two large randomized controlled trials of TAVR that served as the basis for the first FDA approvals of the device (i.e., the Placement of AoRTic TraNscathetER Valve Trial and the U.S. CoreValve High Risk Study) were used to identify hospitals where TAVR had been used experimentally prior to FDA approval $(16,17)$.

\section{Identification of Health Care Markets}

Consistent with multiple prior studies of health care markets, we used the Dartmouth Atlas for Health Care's Hospital Referral Regions (HRRs) as the definition of markets for TAVR (18). These are contiguous geographic areas $(n=306)$ in which the vast majority of Medicare beneficiaries obtain their health care (i.e., travel across HRR boundaries to obtain health care is uncommon), and which have at least one hospital that performs major cardiovascular procedures and neurosurgery, with a minimum population of 120,000. Physician groups were assigned to HRRs based on the physician group's billing ZIP code. Any physician group with billing ZIP codes located in more than one HRR was treated as unrelated, independent practices within each of those HRRs.

\section{Measurement of Physician Group Practice Concentration}

The classical measure of market concentration is the Herfindahl-Hirschman Index (HHI), which is mathematically derived from the observed market share of all competitors in a given market (19). This method results in an endogenous measure of market concentration, because observed market share is a function of unobservable factors (e.g., local reputation, affiliation with a university hospital, perceived quality, etc.) that potentially bias the HHI away from a pure measure of market competition (7). Several prior investigations have addressed this issue by constructing an "exogenous" HHI based solely on the geographic availability of health care providers (i.e. group practices or hospitals) to patients living in ZIP codes within a fixed radius (typically 50 miles) of the provider's ZIP code $(7,8,20)$. We used similar methods (Appendix 2) to construct exogenous HHIs for the current study for both hospitals and for physician groups practices, and these exogenously-constructed HHIs - referred henceforth as $\mathrm{HHI}_{\text {exog }}$-were used as the primary measures of market competition in our analyses. Our $\mathrm{HHI}_{\text {exog }}$ measure was independent of HRR geographic boundaries and solely reflected the choice set of cardiology practices for patients living within 50 miles of each practice.

\section{Medicare Managed Care}

Over 25\% of Medicare Beneficiaries were covered by Medicare managed care during 20122013 (21). We hypothesized that markets with high penetration rates of Medicare managed care may have different rates of TAVR adoption than markets with lower penetration rates, because of the incentives to reduce costs in managed care patients. Hence, we used Medicare's Master Beneficiary Summary Files to calculate county-level measures of Medicare managed care penetration in 2011 to include in our fully-specified models, as well 
as county-level measures of change in Medicare Advantage enrollment between 2011 and 2014.

\section{County-Level Variables}

County-level socioeconomic and health care control variables included per capita income, percentage of the population over age 65 , and educational attainment measures from the 2010 U.S. Census, the county's rural/urban classification (U.S. Department of Agriculture), hospital beds per capita and the presence of a hospital with a coronary care unit as reported in the 2011 American Hospital Association Survey, and physicians per capita (a general measure of health care supply) as reported in the 2010 American Medical Association Physician Masterfile.

\section{TAVR Adoption}

Because most TAVR recipients are older than age 65 (1), the vast majority of TAVR recipients are Medicare beneficiaries, and thus Medicare claims are a comprehensive source of data to measure TAVR adoption. The adoption of TAVR by a physician group practice was indicated by the appearance of a Part B claim for TAVR (CPT codes 0256T, 0257T, or 33361-33366) by at least one physician in the practice after the CMS coverage approval date of $5 / 1 / 2012$.

\section{Statistical Analyses}

We modeled adoption as a Cox proportional hazards time-to-event model, with the dependent variable being the days elapsed between 5/1/2012 and the date of first use of TAVR by a group practice. Practices that had not adopted TAVR at any point during the 32month observation period (i.e., May, 2012 through December, 2014) were censored on $12 / 31 / 2014$. Independent variables in the model included market-level variables (physician group practice $\mathrm{HHI}_{\text {exog }}$, hospital $\mathrm{HHI}_{\text {exog }}$, and the market's population size), group practice characteristics (mean CMS-HCC risk score, interventional case volume, academic hospital affiliation, and TAVR clinical trial hospital affiliation). The full model (detailed specification in Appendix 3) also included the county-level control variables described above. All variables were tested to assure that the proportional hazards assumption (i.e., time independence) was met, and when a time-dependent variable was identified, an interaction with the variable and time was added to the model.

\section{Subgroup Analyses and Robustness Tests}

Because of the regulatory requirement that cardiologists performing TAVR have substantial prior structural heart procedural experience (e.g., catheter-delivered repair of congenital heart defects) (3), we anticipated that physician groups with prior structural heart disease procedural experience may have adopted TAVR at much different rates than physician groups without this prior experience, so a subgroup analysis based on this characteristic was predefined. In addition, because the effect of market competition may have been influenced by managed care penetration, we tested for interaction effects of physician group $\mathrm{HHI}_{\text {exog }}$ with hospital $\mathrm{HHI}_{\text {exog, }}$, physician group $\mathrm{HHI}_{\text {exog }}$ with Medicare Advantage penetration, and 
hospital $\mathrm{HHI}_{\text {exog }}$ with Medicare Advantage penetration. We also conducted robustness checks of our model's specification and functional form.

The University of Pennsylvania's Institutional Review Board approved the research protocol. All analyses were conducted using SAS 9.2 (Cary, NC) and/or Stata 16.1 (College Station, TX).

\section{RESULTS}

We identified 5,116 physician group practices that provided interventional cardiology services in 2011 (Table 1). Thirty percent of these practices were solo-physician, 20\% were affiliated with a teaching hospital, and $75 \%$ performed $>100$ interventional cardiology cases per year. Approximately $10 \%$ of cardiology groups were affiliated with hospitals that had participated in TAVR clinical trials. There was substantial geographic variation in the market concentration of physician groups providing interventional cardiology services at the time of TAVR's introduction (Figure 1); the median interventional cardiology group practice $\mathrm{HHI}_{\text {exog }}$ was 1,600 (IQR 900 to 2,600). Similarly there was substantial variation in the market concentration of hospitals; the median hospital $\mathrm{HHI}_{\text {exog }}$ was 3,100 (IQR 1,900 to 4,700).

\section{Adoption of TAVR by Physician Group Practices}

Among the 5,116 group practices in our study cohort, 475 (9.3\%) practices adopted TAVR during 2012-2014. Among the 274 practices with prior structural heart disease procedural experience, 175 (64\%) adopted TAVR, however among the 4,850 practices without such experience, only $300(6.2 \%)$ adopted TAVR. We observed substantial variation in the proportion of interventional cardiology practices within health care markets (i.e., HRRs) that had adopted TAVR during 2012-2014. Across the 304 HRRs in the contiguous 48 states plus the District of Columbia, the median HRR-level percentage of TAVR adoption was 7.4\% (interquartile range [IQR] $0 \%$ to $15.3 \%$ ). No TAVR adoption occurred in 111 HRRs, while only 1 physician group practice adopted TAVR in 78 HRRs, and $>1$ group practice adopted TAVR in the remaining 115 HRRs.

\section{Unadjusted Association of Market Competition and TAVR Adoption Rates}

Physician group practices in the highest (i.e. most concentrated) tertile for $\mathrm{HHI}_{\text {exog }}$ adopted TAVR at higher rates than practices in the middle or lowest (i.e. most competitive) tertiles for $\mathrm{HHI}_{\text {exog }}$ (log-rank test chi-square=11.24, p=0.004)(Figure 2). By the end of 2014 (974 days after CMS coverage approval), $11.0 \%$ of practices in the most concentrated $\mathrm{HHI}_{\text {exog }}$ tertile had adopted TAVR, compared to $9.1 \%$ of practices in the middle $\mathrm{HHI}_{\text {exog }}$ tertile, and $7.7 \%$ of practices in the lowest $\mathrm{HHI}_{\text {exog }}$ tertile $(\mathrm{p}<0.001)$.

\section{Multivariable Results for Market-level Concentration}

Tests of correlation among our independent variables revealed no substantial multicollinearity (i.e. all variance inflation factors $<2.5$ ). The fully-specified multivariable model (Table 2) revealed a hazard ratio of 1.26 (95\% confidence interval[CI] 1.16 to 1.37 , $\mathrm{p}<0.001$ ) per 1,000 increase in physician group practice $\mathrm{HHI}_{\text {exog }}$, indicating each 1,000 
increase in group practice $\mathrm{HHI}_{\text {exog }}$ was associated with a $26 \%$ higher rate of TAVR adoption. Conversely, the hazard ratio for hospital $\mathrm{HHI}_{\text {exog }}$ was 0.90 (95\% CI 0.83 to 0.98 , $\mathrm{p}=0.02$ ), indicating each 1,000 increase in hospital $\mathrm{HHI}_{\text {exog }}$ resulted in a $10 \%$ lower rate of TAVR adoption. The inclusion of additional control variables in our models had minimal impact on the magnitude of the measured effect of $\mathrm{HHI}_{\text {exog }}$ for both physician group practices and hospitals. We also observed a hazard ratio of 1.25 (95\% CI 1.15 to 1.37, $\mathrm{p}<0.001)$ for managed care penetration, indicating each 10 percentage point increase in (county-level) managed care penetration was associated with a $25 \%$ relative increase in the rate of TAVR adoption.

\section{Subgroup Analysis}

Because prior experience with structural heart repair by the interventional cardiologist performing TAVR was a requirement in the CMS National Coverage Determination for TAVR, we expected that TAVR adoption rates would differ markedly between physician group practices with prior structural heart repair experience versus those practices that lacked prior structural heart experience (the latter practices would presumably have had to recruit an interventional cardiologist with the necessary procedural experience in order to offer TAVR services). We therefore analyzed TAVR adoption of these two subgroups (Appendix 4). The subgroup results showed a very similar pattern of increased adoption of TAVR in markets with greater physician group concentration, with the hazard ratio for TAVR adoption per 1,000 increase in $\mathrm{HRR}_{\text {exog }}=1.19(\mathrm{p}=0.07)$ in the 266 physician groups with prior structural heart repair experience, and $1.21(\mathrm{p}=0.001)$ in the 4,632 physician groups without prior structural heart repair experience.

\section{Robustness}

Variation in functional form and model specification, as well as subgroup testing, produced no material differences in the direction or statistical significance of the relationship between $\mathrm{HHI}_{\text {exog }}$ and TAVR adoption (Appendix 3).

\section{DISCUSSION}

Adoption of TAVR was more common in 2012-2014 by physician groups located in health care markets that were less competitive, a result that was consistent across subgroups and robust to the choices of functional form and specification of our analytic models. This finding is contrary to the "Medical Arms Race" paradigm that has been the leading theoretical construct explaining the relationship between market concentration and technology adoption. A secondary finding is that TAVR adoption was more common by physician groups located in markets with higher managed care penetration, a finding also at odds with previous work suggesting managed care slows adoption of high-technology medical services.

\section{Why TAVR was Adopted by Physician Groups in less Competitive Markets}

There are unique aspects to TAVR and the national coverage determination regulations governing its use that may explain its more frequent adoption in more monopolistic markets. First, CMS required TAVR to be performed by interventional cardiologists with at least 100 
prior structural heart procedures. It is possible that physician group practices having a dominant share of interventional procedures in their market were more likely to have members of the group who met these stringent qualifications. Conversely, group practices in competitive markets with smaller market shares may have struggled to meet the procedural volume requirements. Second, it is possible that within any given market there was a particular benefit to being among the first physician groups to offer TAVR, because establishment of a successful TAVR program requires an ample supply of qualified patients, and these patients may have been harder to attract in markets that already had active TAVR providers. The opportunity to become the first TAVR-providing entrant in a market was more common in markets with fewer competitors. A third possibility is that TAVR services required an investment on the part of physician group practices in the acquisition of new skills by designated members of the practice, and/or by recruitment of physicians with these skills to the practice. It is possible that the resources needed for this up-front investment in additional training/recruitment and knowledge/skills acquisition were primarily available at group practices in concentrated markets, where practice profits would be expected to be higher than in more competitive markets. This explanation is well-aligned with Rogers' classic theory of innovation adoption, whereby innovators have higher tolerance for risk in part because of their greater financial resources (22). A final possibility is that TAVR may not have been an attractive additional service for interventional cardiology groups in competitive markets, since from the practice's perspective it was unclear whether the monetary and non-monetary (i.e. prestige) benefits of offering TAVR outweighed the opportunity costs of providing the service.

\section{Managed Care Penetration and TAVR Adoption}

The association between managed care penetration and TAVR adoption was also unexpected because prior studies found that managed care slows the adoption of new technology, potentially because manage care enhances competition on price rather than high-technology services (23-26). However for TAVR, it is possible that the increased coordination of care in markets with higher managed care penetration facilitated partnerships among hospitals, cardiologists, and surgeons that were necessary to provide TAVR.

\section{Comparisons with Prior Findings}

Empirical studies supporting the Medical Arms Race theory have largely focused on the actions of hospitals. Robinson and Luft determined that hospitals in competitive environments more frequently adopted high-cost technologies such as MRIs (10). Kessler and McClellan subsequently found that hospitals similarly adopted higher-cost therapies for care of acute myocardial infarction in localities with greater competition (8). More recently Devers and colleagues found evidence of competition encouraging technology adoption (6), and Berenson et al. found similar practices among hospital service lines (5). Our study differs from the majority of the existing literature by our focus on physician groups, and because of the unique policies governing the adoption of TAVR implemented by CMS, the dominant national payer because TAVR in 2012-2014 was primarily a technology used in elderly patients. Strobel et al. examined TAVR adoption in five states and found that higher hospital competition was associated with more rapid adoption (27). Our findings for hospitals were concordant with these prior findings-we also observed that hospitals in 
competitive markets nationwide adopted TAVR more readily. However, physician group practices behaved differently.

\section{Limitations}

It is appropriate to acknowledge several limitations to the current study. The internal validity of our use of TINs to indicate physician group affiliation ignores the possibility of multiple TINs being part of a single organization, hence the true number of independent groups is likely smaller than our analyses assume. Similarly, accurate measurement of TAVR adoption by physician groups with extremely high managed care penetration among their Medicare patients may have been impeded because our detection of TAVR adoption depended on the existence of Part B (i.e., fee-for-service claims), which are not generated for Medicare Advantage enrollees. However this would be expected to bias the findings toward lower adoption rates in high-Medicare-Advantage areas, rather than the higher rates that we observed. Our study did not incorporate the construct of "vertical integration," i.e. physician group practices being acquired by hospitals and health systems during 2011-14 (28), and this phenomenon could have influenced the relationship between physician group competition and TAVR adoption. Finally, the uniqueness of policies governing TAVR adoption affects our study's external validity, and thus our findings may not apply to the diffusion of other medical technologies, nor to more recent TAVR adoption since 2014.

\section{Conclusion}

Adoption of TAVR was more common in medical markets with higher concentration of interventional cardiology physician groups. This finding challenges the standard "Medical Arms Race" assumption that competitive markets incentivize the adoption of advanced medical technology, ultimately leading to inappropriate medical resource use. Our findings suggest that the Medical Arms Race is not the governing paradigm in all cases of technology diffusion in fee-for-service environments. In fact, it is possible that physician group practices in highly competitive markets may have lacked the necessary CMS-imposed regulatory qualifications to provide TAVR expeditiously to patients who might have benefited from it.

\section{Supplementary Material}

Refer to Web version on PubMed Central for supplementary material.

\section{Acknowledgments}

Funding: Agency for Healthcare Research and Quality Grant \#1R01-HS023615

\section{REFERENCES}

1. Mack MJ, Brennan JM, Brindis R, et al. Outcomes following transcatheter aortic valve replacement in the United States. JAMA 2013;310:2069-2077 [PubMed: 24240934]

2. Food and Drug Administration. Notice of Premarket Approval. 2011 Available at: https:// www.accessdata.fda.gov/cdrh_docs/pdf10/P100041A.pdf. Accessed October 25, 2019

3. Centers for Medicare and Medicaid Services. National Coverage Determination Decision Memo for Transcatheter Aortic Valve Replacement (CAG-00430N). 2012 Available at: https://www.cms.gov/ medicare-coverage-database/details/nca-decision-memo.aspx?NCAId=257. Accessed October 25, 2019 
4. Centers for Medicare and Medicaid Services. Calendar Year 2012 Physician Fee Schedule (PFS) final rule. 2012 Available at: https://www.cms.gov/Medicare/Medicare-Fee-for-Service-Payment/ PhysicianFeeSched/PFS-Federal-Regulation-Notices-Items/CMS1253669.html. Accessed October 21, 2019

5. Berenson RA, Bodenheimer T, Pham HH. Specialty-service lines: salvos in the new medical arms race. Health Aff (Millwood) 2006;25:w337-343 [PubMed: 16868008]

6. Devers KJ, Brewster LR, Casalino LP. Changes in Hospital Competitive Strategy: A New Medical Arms Race? Health Serv Res 2003;38:447-469 [PubMed: 12650375]

7. Karaca-Mandic P, Town RJ, Wilcock A. The Effect of Physician and Hospital Market Structure on Medical Technology Diffusion. Health Serv Res 2017;52:579-598 [PubMed: 27196678]

8. Kessler DP, McClellan MB. Is Hospital Competition Socially Wasteful? Q J Econ 2000;115:577615

9. Robinson JC, Luft HS. The impact of hospital market structure on patient volume, average length of stay, and the cost of care. J Health Econ 1985;4:333-356 [PubMed: 10276358]

10. Robinson JC, Luft HS. Competition and the cost of hospital care, 1972 to 1982. JAMA 1987;257:3241-3245 [PubMed: 3586247]

11. Luft HS, Garnick DW, Hughes RG, et al. Hospital competition, cost, and medical practice. J Med Pract Manage 1988;4:10-15 [PubMed: 10302768]

12. Bates LJ, Mukherjee K, Santerre RE. Market structure and technical efficiency in the hospital services industry: a DEA approach. Med Care Res Rev 2006;63:499-524 [PubMed: 16847075]

13. Birkmeyer JD, Stukel TA, Siewers AE, et al. Surgeon volume and operative mortality in the United States. N Engl J Med 2003;349:2117-2127 [PubMed: 14645640]

14. Kilic A, Shah AS, Conte JV, et al. Operative outcomes in mitral valve surgery: combined effect of surgeon and hospital volume in a population-based analysis. J Thorac Cardiovasc Surg 2013;146:638-646 [PubMed: 22914251]

15. Centers for Medicare and Medicaid Services. Hierarchical Condition Category 2006-2011 Model Software/ICD-9-CM Mappings. 2011 Available at: https://www.cms.gov/Medicare/Health-Plans/ MedicareAdvtgSpecRateStats/Risk-Adjustors-Items/Risk2006-2011.html? DLPage $=2 \&$ DLEntries $=10 \& D L S o r t=0 \& D L S o r t D i r=$ descending. Accessed October 18, 2019

16. Adams DH, Popma JJ, Reardon MJ, et al. Transcatheter aortic-valve replacement with a selfexpanding prosthesis. N Engl J Med 2014;370:1790-1798 [PubMed: 24678937]

17. Smith CR, Leon MB, Mack MJ, et al. Transcatheter versus surgical aortic-valve replacement in high-risk patients. N Engl J Med 2011;364:2187-2198 [PubMed: 21639811]

18. The Dartmouth Atlas of Health Care, 1999. Chicago: American Hospital Publishing; 1999

19. Fulton BD. Health Care Market Concentration Trends In The United States: Evidence And Policy Responses. Health Aff (Millwood) 2017;36:1530-1538 [PubMed: 28874478]

20. Gowrisankaran G, Town RJ. Competition, payers, and hospital quality. Health Serv Res 2003;38:1403-1421 [PubMed: 14727780]

21. Jacobson G. DA Neuman T. A dozen facts about Medicare Advantage. 2018 Available at: https:// www.kff.org/medicare/issue-brief/a-dozen-facts-about-medicare-advantage/. Accessed November 19, 2019

22. Rogers EM. Diffusion of Innovations, 5th ed New York: Free Press; 2003

23. Baker LC, Phibbs CS. Managed care, technology adoption, and health care: the adoption of neonatal intensive care. Rand J Econ 2002;33:524-548 [PubMed: 12585306]

24. Baker LC, Wheeler SK. Managed care and technology diffusion: the case of MRI. Health Aff (Millwood) 1998;17:195-207 [PubMed: 9769583]

25. Ramsey SD, Hillman AL, Pauly MV. The effects of health insurance on access to new medical technologies. Int J Technol Assess Health Care 1997;13:357-367 [PubMed: 9194356]

26. Ramsey SD, Pauly MV. Structural incentives and adoption of medical technologies in HMO and fee-for-service health insurance plans. Inquiry 1997;34:228-236 [PubMed: 9349247]

27. Strobel RJ, Likosky DS, Brescia AA, et al. The Effect of Hospital Market Competition on the Adoption of Transcatheter Aortic Valve Replacement. Ann Thorac Surg 2020;109:473-479 [PubMed: 31394089] 
28. Song Z, Wallace J, Neprash HT, et al. Medicare Fee Cuts and Cardiologist-Hospital Integration. JAMA Intern Med 2015;175:1229-1231 [PubMed: 26011666] 


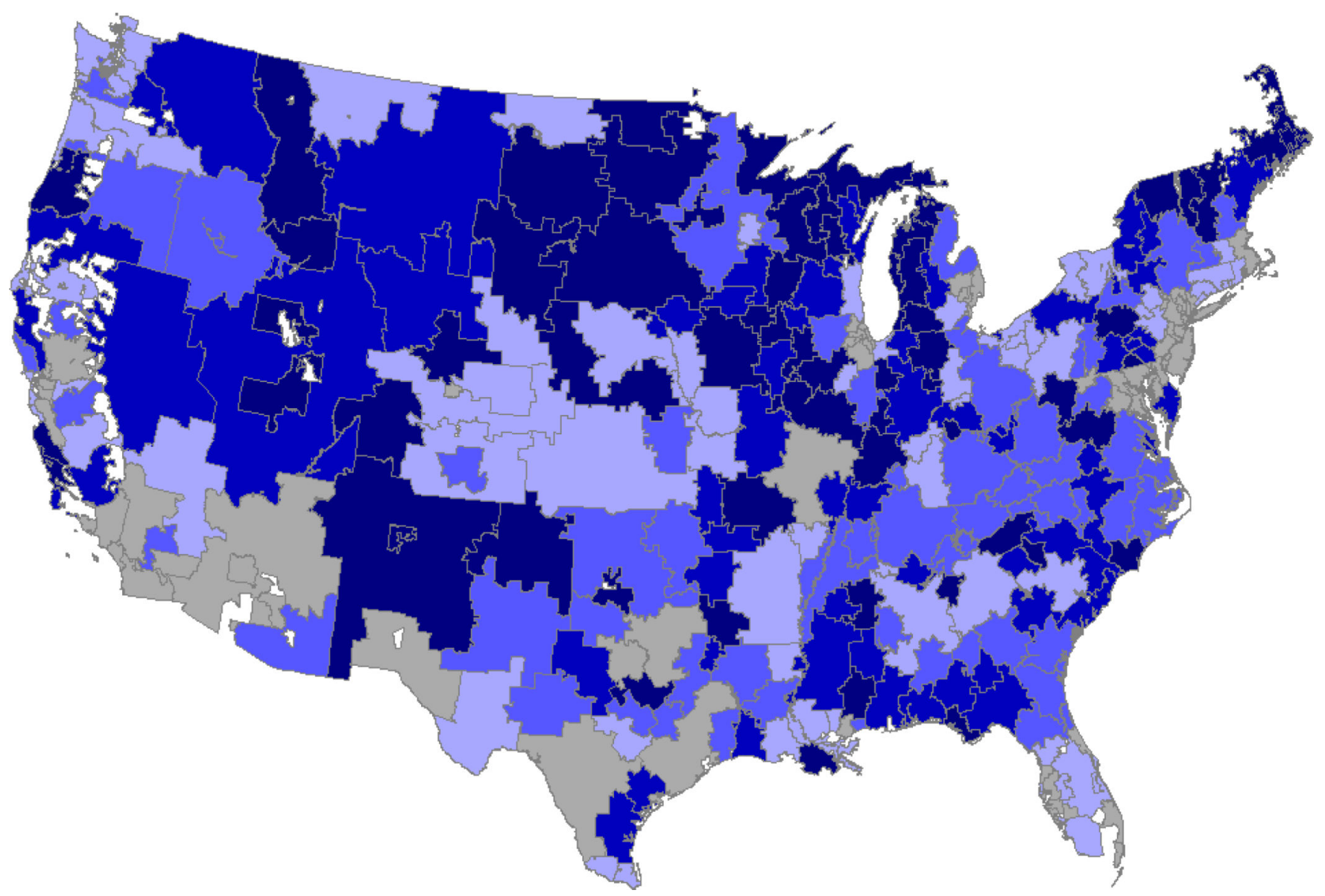

Figure 1. Market Concentration of Interventional Cardiology Physician Group Practices Among U.S. Health Care Markets.

Health care markets, defined as the 304 Hospital Referral Regions in the 48 contiguous

United States and the District of Columbia, are shaded by quintile of mean $\mathrm{HHI}_{\text {exog }}$ in each HRR for physician group practices that offered interventional cardiology services. Gray indicates the lowest $\mathrm{HHI}_{\text {exog }}$ level (i.e., the most competitive markets; $\mathrm{HHI}_{\text {exog }}=500$ to 1,500 ), while increasingly darker shades of blue indicate greater market concentration (i.e., less competitive markets). Pale blue indicates $\mathrm{HHI}_{\text {exog }}=1,500$ to 2,200, light blue indicates $\mathrm{HHI}_{\text {exog }}=2,200$ to 3,100, blue indicates $\mathrm{HHI}_{\text {exog }}=3,100$ to 4,000, and dark blue indicates $\mathrm{HHI}_{\text {exog }}=4,000$ to 10,000 . 

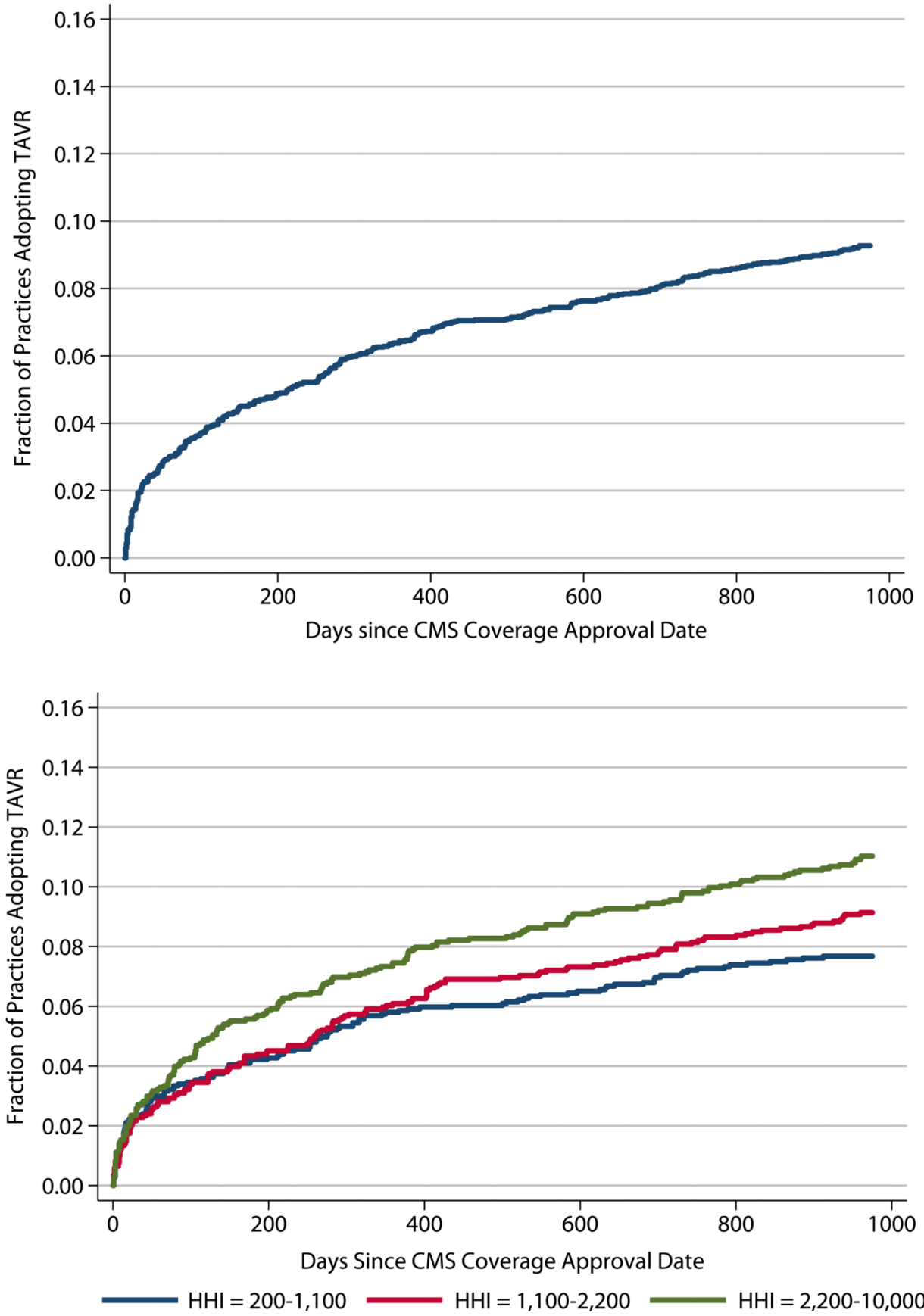

Figure 2. Unadjusted Adoption of TAVR from 2012-2014 by Physician Group Practices offering Interventional Cardiology Services, Overall and by Tertile.

The upper panel indicates the fraction of all physician group practices, as indicated on the $\mathrm{Y}$ axis, that offered interventional cardiology services that had submitted at least one Part B claim to Medicare for TAVR by the date indicated on the $\mathrm{X}$ axis. The lower panel shows the adoption rate among 3 equal-sized subgroups of practices located in health care markets with high concentration (green), moderate concentration (red), and low concentration (blue) of physician group practices, as defined by tertiles of $\mathrm{HHI}_{\mathrm{exog}}$. 
Table 1.

Interventional Cardiology Group Characteristics

\begin{tabular}{|c|c|}
\hline \multirow{2}{*}{ Characteristic } & n $(\%)$ \\
\hline & Practices $(n=5,116)$ \\
\hline \multicolumn{2}{|c|}{ Number of physicians per physician group practice in 2011} \\
\hline 1 & $1,534(30)$ \\
\hline $2-5$ & $1,116(22)$ \\
\hline $6-20$ & $846(17)$ \\
\hline $21-50$ & $477(9)$ \\
\hline $51-100$ & $373(7)$ \\
\hline$>100$ & $770(15)$ \\
\hline \multicolumn{2}{|c|}{ Annual case volume per physician group practice in $2011^{a}$} \\
\hline $1-99$ & $1,289(25)$ \\
\hline $100-199$ & $1,399(27)$ \\
\hline $200-399$ & $1,637(32)$ \\
\hline $400-699$ & $607(12)$ \\
\hline $700-999$ & $136(3)$ \\
\hline $1,000-1,999$ & $52(1)$ \\
\hline$\geq 2,000$ & $4(0.1)$ \\
\hline \multicolumn{2}{|c|}{ Annual case volume per interventional cardiologist in 2011} \\
\hline $1-100$ & $1,502(29)$ \\
\hline $101-200$ & $1,526(29)$ \\
\hline $201-400$ & $1,348(27)$ \\
\hline$>400$ & $740(15)$ \\
\hline \multicolumn{2}{|c|}{ U.S. Census region } \\
\hline Midwest & $1,047(20)$ \\
\hline South & $2,063(40)$ \\
\hline Northeast & $940(19)$ \\
\hline West & $1,066(21)$ \\
\hline Urban location $^{b}$ & $2,867(56)$ \\
\hline Physician Group affiliated with academic hospital ${ }^{c}$ & $1,038(20)$ \\
\hline Physician Group affiliated with a TAVR clinical trial hospital ${ }^{d}$ & $505(10)$ \\
\hline \multicolumn{2}{|c|}{ Mean HCC risk quartile (range of HCC risk scores) } \\
\hline Highest (2.97-7.63) & $1,280(25)$ \\
\hline Second (2.60-2.97) & $1,279(25)$ \\
\hline Third (2.30-2.60) & $1,279(25)$ \\
\hline Lowest $(0.75-2.30)$ & $1,278(25)$ \\
\hline
\end{tabular}

Med Care. Author manuscript; available in PMC 2021 November 01. 


\begin{tabular}{lc}
\hline Characteristic & $\mathbf{n}(\boldsymbol{\%})$ \\
\hline 50,000 & Practices (n=5,116) \\
\hline$>50,000-100,000$ & $\mathbf{7 8 1}(\mathbf{1 5})$ \\
\hline$>100,000-200,000$ & $1,201(24)$ \\
\hline$>200,000-400,000$ & $1,513(30)$ \\
\hline$>400,000$ & $1,082(21)$ \\
\hline Percentage of Medicare Beneficiaries in each Physician Group Practice's County Enrolled in Medicare Advantage \\
\hline$\leq 0$ & $539(11)$ \\
\hline$>10-20$ & $1,322(26)$ \\
\hline$>20-30$ & $1,131(22)$ \\
\hline$>30-40$ & $1,127(22)$ \\
\hline$>40-50$ & $667(13)$ \\
\hline$>50$ & $297(6)$ \\
\hline $8,000-10,000$ & $3,134(61)$ \\
\hline $0-1,999$ & $1,469(29)$ \\
\hline $2,000-3,999$ & $396(7.7)$ \\
\hline $4,000-5,999$ & $94(1.8)$ \\
\hline $6,000-7,999$ & $26(0.5)$ \\
\hline
\end{tabular}

${ }^{a}$ Case volume for interventional cardiology procedures in 2011 among fee-for-service Medicare beneficiaries.

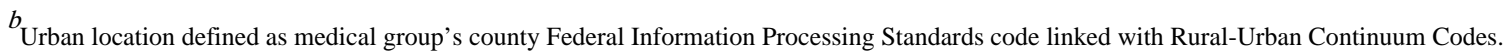

${ }^{c}$ Academic hospitals defined as members of the Council of Teaching Hospitals and Health Systems.

${ }^{d}$ Physicians affiliated with hospitals that participated in the TAVR Clinical Trial Hospitals prior to the FDA approval of TAVR, i.e. the Placement of AoRTic TraNscathetER Valve Trial (PARTNER) and the U.S. CoreValve High Risk Study.

Abbreviations: TAVR = Transcatheter Aortic Valve Replacement; HCC = Centers for Medicare and Medicaid Services Hierarchical Condition Category; HHI $_{\text {exog }}=$ Exogenous Herfindahl-Hirschman Index. 


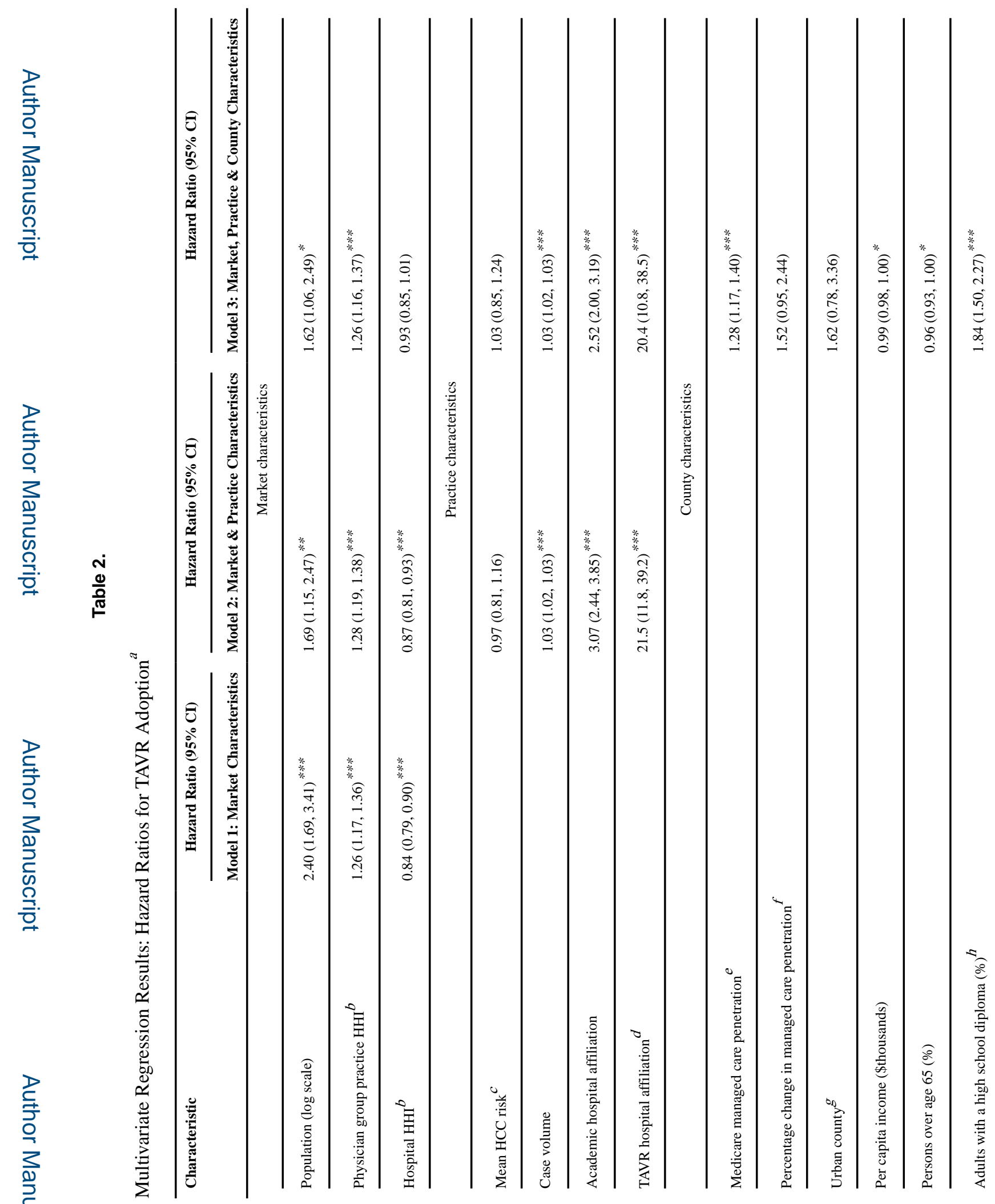




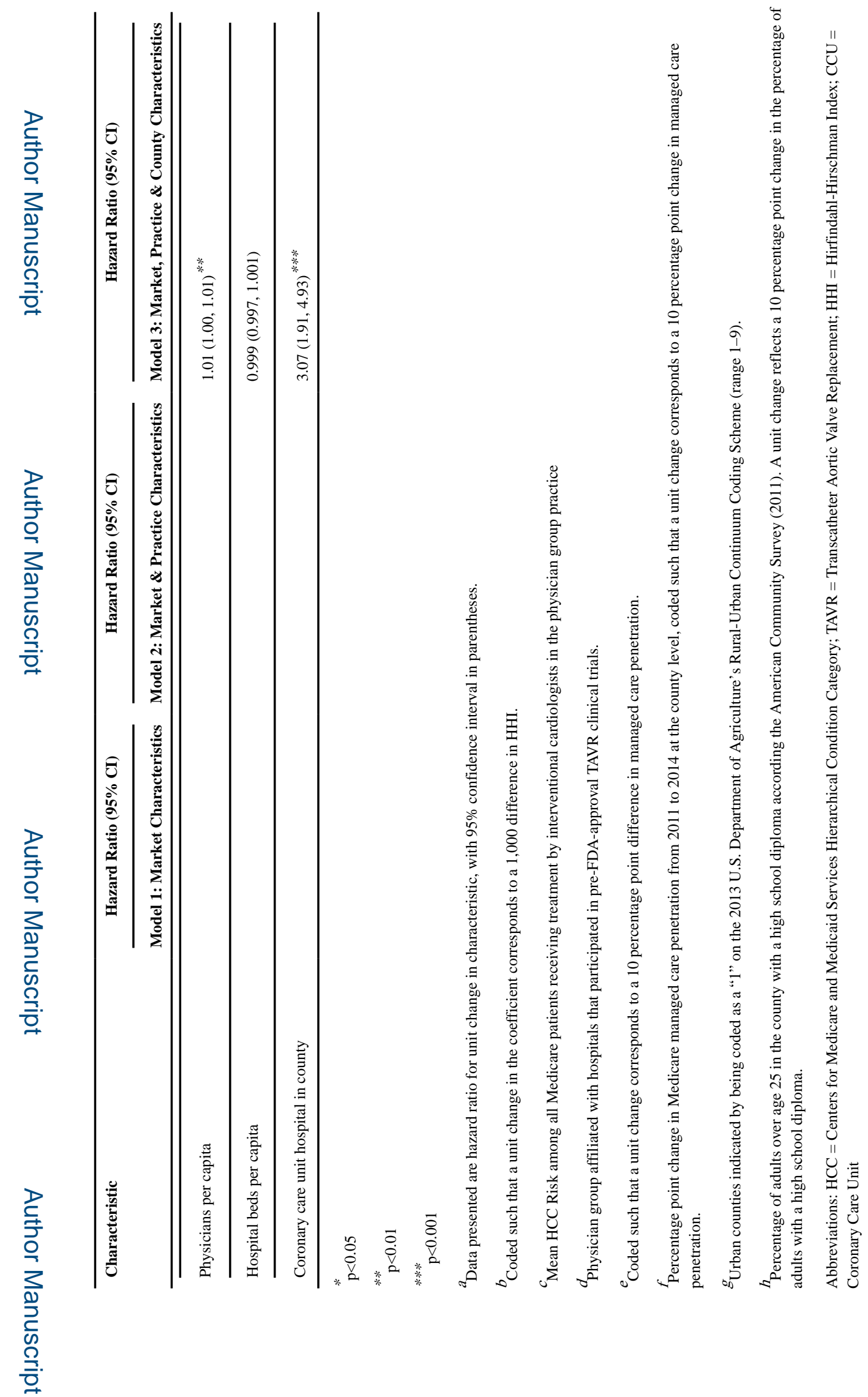

Med Care. Author manuscript; available in PMC 2021 November 01. 